\title{
A STUDY ON PERINATAL MORTALITIES AND ITS DETERMINANTS AT A TERTIARY HOSPITAL IN A METROPOLITAN CITY.
}

\section{Gynaecology}

\section{Devalla Anusha}

Wani Reena J*
Senior Resident, Dept Of Obstetrics And Gynaecology Dr R.N. Cooper Hospital and HBTH Medical College, Juhu Mumbai

Head Of The Department, Department Of Obstetrics And Gynaecology Dr R.N. Cooper Hospital and HBTH Medical College, Juhu Mumbai *Corresponding Author

\section{ABSTRACT}

The aim of the study is to estimate the perinatal mortality rate and its determinants. A retrospective observational study was conducted at a tertiary hospital in Maharashtra, India of the perinatal mortalities born from January 2017 to December 2017 after Ethics Committee approval. Data was acquired from the Delivery register of the Labour room covering the maternal socio-demographic characteristics and the relevant investigations. The causes of perinatal mortality were simplified as per the Tulip Classification (2006). Statistical Analysis: The standard WHO formula for calculating the perinatal mortality rate was applied. Chi- square test followed by P-value were obtained through the Open Epi software, was used for estimating the statistically significant observations amongst the study results. The total births in the study period were 3461 and the perinatal deaths were 132. The Perinatal Mortality Rate computed to 39.65 per 1000 live births. Out of the 132 perinatal deaths, stillbirths were 89 and early neonatal deaths were 43. The perinatal mortalities were found to be highest in the age group of 30-35 years, multigravidae, unbooked and high risk obstetric patients and low birth weight newborns. Lack of antenatal registrations, unoptimised high risk pregnancies entering labour can potentially pose a threat to the delivery outcome.

\section{KEYWORDS}

Tertiary Hospital, Perinatal Mortality; Prematurity; Tulip Classification

\section{INTRODUCTION}

Perinatal mortality is defined (WHO) as late fetal deaths that occur beyond the period of viability ( $>28$ weeks and/or 1000 grams) and neonatal death within the first seven days of life. It has been observed that perinatal mortality holds a major public health challenge in many low and middle income countries (LMICs), therefore, one of the strategies of Millennium Development Goals (MDG-4). ${ }^{1}$ Perinatal mortality rate (PMR) is the one of the most sensitive index of the efficacy of not only the antenatal, intranatal care and the quality of child health but also the socioeconomic status of the community.

Although newborn care is an essential element to reduce the perinatal mortality, it often receives less than optimum attention. Almost half of the perinatal mortality occurs during the period of labour and delivery. A wide spectrum of causes is known to affect the perinatal mortality rates that may also be influenced by the maternal, social and circumstantial factors. Some of the established causes include Hypertensive disorders, Antepartum haemorrhage, Intrapartum asphyxia, Preterm labour, fetal abnormality, maternal infection and IUGR.

This study aims to enlighten the causes of perinatal mortalities at a tertiary hospital in Maharashtra, India

\section{MATERIALS AND METHODS}

This is a yearly study from January 2017 to December 2017 done among all births at a tertiary care hospital in Maharashtra, western India. The population of the metropolitan city was estimated to be 23.5 million in the same year as extrapolated from the 2017 census. During the study period, 3461 were delivered after 28 week of gestation. The number of perinatal mortalities was 132; the PMR being and the adjusted PMR (after excluding the congenital anomalies which were incompatible with life) were 39.65 and 36.94 respectively.

Some of the data collected include maternal age, booking status, parity, gestational age, mode of delivery, birth weight, and requirement of NICU admissions, obstetric and medical complications in the mother.

Ethical approval and clearance was obtained from the Institutional review board. Since the analysis used entirely the registered data from the Labour room statistics, it didn't require informed consent; however, the confidentiality was maintained.

Table 2- Showing the distribution of low birth weight newborns according to gestational age and the distribution of the perinatal deaths in each category.

\begin{tabular}{|c|c|c|c|c|c|c|c|}
\hline \multirow{2}{*}{$\begin{array}{l}\text { Low Birth Weight } \\
\text { Newborns }\end{array}$} & \multicolumn{3}{|c|}{ Gestational age as per menstrual age at delivery(preterm/term/post term) } & \multirow[t]{2}{*}{ Alive } & \multirow[t]{2}{*}{ Stillbirth } & \multirow[t]{2}{*}{ Neonatal deaths } & \multirow[t]{2}{*}{ Total } \\
\hline & $\begin{array}{c}\text { Preterm } \\
\text { (less than } 37 \text { weeks) }\end{array}$ & $\begin{array}{c}\text { Term } \\
(>/=37 \text { weeks till } 42 \text { weeks })\end{array}$ & $\begin{array}{c}\text { Post term } \\
(>/=42 \text { weeks })\end{array}$ & & & & \\
\hline
\end{tabular}

The data was entered, coded and analysed using the SPS version 16.0 computer software program, chi square test applied and P-value computed. $\mathrm{P}$-value $<0.05$ was taken as statistically significant.

\section{RESULTS}

The estimated population of the metropolitan city in Maharashtra was 23.5 million in the year 2017. The total number of births in the year 2017 was 3461 , live birth was 3329 and perinatal deaths were 132 . The number of stillbirths computed to be 89 and early neonatal deaths were 43 .

Perinatal mortality rate (was calculated by the WHO formula) PMR $=$ number of stillbirths +early neonatal deaths $/ 1000$ live births

$=89+43=132 / 3329 \times 1000=39.65$

The total congenital anomalies incompatible with life were 9 , hence excluding them from the total perinatal mortalities $=132-9=123$

The adjusted perinatal mortality rate, after deducting the congenital anomalies incompatible with life, was $=123 / 3329 \times 1000=36.94$

The stillbirth rate $=89 / 3329 \times 1000=0.02 \%$

The early neonatal death rate $=43 / 3329 \times 1000=0.01 \%$. The macerated and fresh stillbirths were found to be 59 and 30 respectively.

Table 1- shows Mode of delivery of all the births (included in the study)

\begin{tabular}{|c|c|c|c|c|}
\hline Type of \\
delivery & \multicolumn{5}{|c|}{ Outcome } \\
\cline { 2 - 5 } & Alive & Stillbirth & $\begin{array}{c}\text { Neonatal } \\
\text { deaths }\end{array}$ & Total (\%) \\
\hline $\begin{array}{c}\text { Normal } \\
\text { Vaginal } \\
\text { deliveries }\end{array}$ & 2188 & 72 & 29 & $2289(66.13 \%)$ \\
\hline $\begin{array}{c}\text { Caesarean } \\
\text { section }\end{array}$ & 1122 & 17 & 13 & $1152(33.28 \%)$ \\
\hline $\begin{array}{c}\text { Instrumental } \\
\text { deliveries }\end{array}$ & 19 & 0 & 1 & $20(0.57 \%)$ \\
\hline Total & $3329(96.18 \%)$ & $89(2.5 \%)$ & $43(1.2 \%)$ & $3461(100 \%)$ \\
\hline
\end{tabular}




\begin{tabular}{|c|c|c|c|c|c|c|c|}
\hline $\begin{array}{c}\text { Less than or equal to } \\
1.5 \mathrm{~kg}\end{array}$ & 582 & 151 & 1 & 655 & 53 & 26 & 734 \\
\hline $\begin{array}{c}\text { More than } 1.5 \mathrm{~kg}(\text { less } \\
\text { than } 2.5 \mathrm{~kg} \text { ) }\end{array}$ & 893 & 513 & 3 & 1392 & 12 & 5 & 1409 \\
\hline Total & 1475 & 664 & 4 & 2047 & 65 & 31 & 2143 \\
\hline \multicolumn{7}{|c|}{$\begin{array}{c}\text { Chi- square } 7.442 \\
\text { Degrees of freedom-2 } \\
\text { P-value- } 0.02421\end{array}$} \\
\hline
\end{tabular}

The number of stillbirths was the highest in the very low birth weight category with 49 in the preterm category and four in the term category and neonatal deaths were 19 in the preterm and seven in the term group. Majority of the preterm neonatal deaths were secondary to pulmonary haemorrhage and septicaemia (asphyxia).

Table 3- shows distribution of perinatal mortalities according to maternal age groups

\begin{tabular}{|c|c|c|c|c|}
\hline Age/Outcome & Alive & Perinatal mortalities (\%) & Total births & $\begin{array}{c}\% \text { contribution of each group( to the } \\
\text { confinement rate) }\end{array}$ \\
\hline Less than 20 years & 109 & $3(2.67 \%)$ & 112 & $3.2 \%$ \\
\hline $20-25$ years & 631 & $14(2.17 \%)$ & 645 & $18.6 \%$ \\
\hline $25-30$ years & 1375 & $49(3.44 \%)$ & 1424 & $31.14 \%$ \\
\hline $30-35$ years & 1090 & $61(5.29 \%)$ & 1151 & $2.97 \%$ \\
\hline $35-40$ years & 99 & $4(3.88 \%)$ & 26 & $0.75 \%$ \\
\hline $40-45$ years & 25 & $1(3.84 \%)$ & 3461 & $100 \%$ \\
\hline Total & 3329 & $132(3.81 \%)$ & \\
\hline & $\begin{array}{c}\text { Chi square- } 12.61 \\
\text { Pegrees of freedom- }-5\end{array}$ \\
\hline
\end{tabular}

Table 4- shows categorization of the various causes of perinatal mortalities (TULIP classification )

\begin{tabular}{|c|c|c|c|c|}
\hline Cause of death & n (\% of total) & Sub classification & & $\mathrm{N}$ \\
\hline \multirow[t]{15}{*}{1 Congenital anomaly } & \multirow[t]{15}{*}{9} & 1 Chromosomal defects & $\begin{array}{l}1 \text { Numerical } \\
\text { 2 Structural } \\
\text { 3Microdeletion/uniparental disomic }\end{array}$ & - \\
\hline & & & & - \\
\hline & & & & - \\
\hline & & 2 Syndrome & $\begin{array}{l}1 \text { Monogenic } \\
2 \text { Other }\end{array}$ & - \\
\hline & & & & - \\
\hline & & 3 Central nervous system & & 7 \\
\hline & & 4 Heart and circulatory system & & 1 \\
\hline & & 5 Respiratory system & & - \\
\hline & & 6 Digestive system & & - \\
\hline & & 7 Urogenital system & & 1 \\
\hline & & 8 Musculoskeletal system & & - \\
\hline & & 9 Endocrine/metabolic system & & - \\
\hline & & 10 Neoplasm & & - \\
\hline & & 11 Other & $\begin{array}{l}1 \text { Single organ } \\
2 \text { Multiple organ }\end{array}$ & - \\
\hline & & & & - \\
\hline \multirow[t]{6}{*}{2 Placenta } & \multirow[t]{6}{*}{26} & 1 Placental bed pathology & & 15 \\
\hline & & 2 Placental pathology & $\begin{array}{l}1 \text { Development } \\
2 \text { Parenchyma } \\
3 \text { Localisation }\end{array}$ & - \\
\hline & & & & 5 \\
\hline & & & & - \\
\hline & & 3 Umbilical cord complication & & 1 \\
\hline & & 4 NOS(meconium stained liquor) & & 5 \\
\hline \multirow[t]{5}{*}{ 3Prematurity/immaturity } & \multirow[t]{5}{*}{28} & 1 PPROM & & 12 \\
\hline & & 2 Preterm labour & & 14 \\
\hline & & 3 Cervical dysfunction & & 2 \\
\hline & & 4 Iatrogenic & & - \\
\hline & & $5 \mathrm{NOS}$ & & - \\
\hline 4 Infection & 7 & $\begin{array}{l}1 \text { Transplacental(Malaria, } \\
\text { Dengue) }\end{array}$ & & 2 \\
\hline
\end{tabular}




\begin{tabular}{|c|c|c|c|c|}
\hline & & 2 Ascending & & 2 \\
\hline & & 3 Neonatal & & 2 \\
\hline & & 4 NOS(HIV) & & 1 \\
\hline \multirow[t]{5}{*}{5 Other } & \multirow[t]{5}{*}{17} & $\begin{array}{l}1 \text { Fetal hydrops of unknown } \\
\text { origin }\end{array}$ & & 4 \\
\hline & & 2 Maternal disease & & 11 \\
\hline & & 3 Trauma & $\begin{array}{l}1 \text { Maternal } \\
2 \text { Fetal }\end{array}$ & - \\
\hline & & & & - \\
\hline & & $\begin{array}{l}4 \text { Out of the ordinary(milk } \\
\text { aspiration) }\end{array}$ & & 2 \\
\hline \multirow[t]{2}{*}{6 Unknown } & \multirow[t]{2}{*}{44} & 1 Despite thorough investigation & & 11 \\
\hline & & 2 Important information missing & & 31 \\
\hline Total & 132 & & & 132 \\
\hline
\end{tabular}

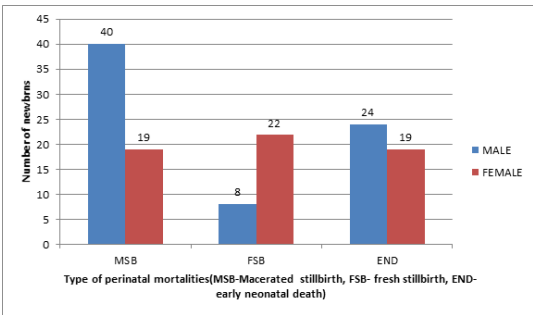

Graph 1- Shows the quantitative comparison of perinatal mortalities

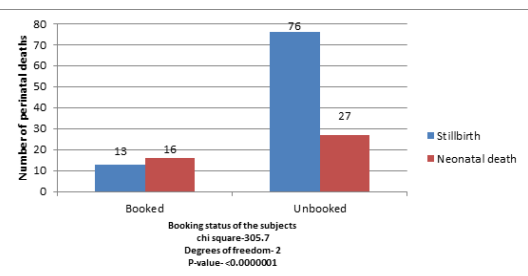

Graph 2- shows the number of perinatal mortalities according to the booking status (A patient was considered booked if she had minimum three antenatal visits)

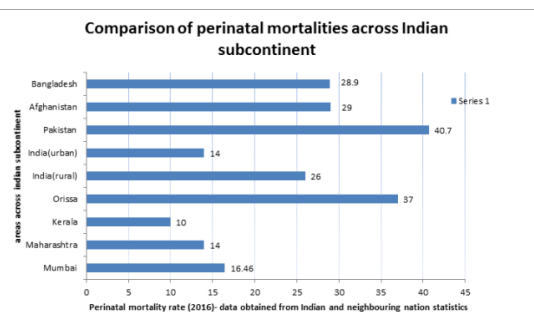

Graph 3- shows comparison of perinatal mortality rates across various countries of Indian sub-continent.

\section{DISCUSSION}

WHO defines perinatal mortality as the "number of stillbirths and early neonatal deaths per 1000 total live births, the perinatal period beginning at 28 completed weeks of gestation and ending seven completed days after birth."

About 0.75 million neonates die every year in India, the highest for any country in the world. ${ }^{4}$

Early Neonatal mortality rate was found to be 22 per 1000 live births, deaths in the first week alone account for $\sim 45 \%$ of total under-five deaths. ${ }^{5}$

The PMR is five times higher in developing than in developed nations (10 per 1000 and 50 per 1000 total births in developed and developing nations, respectively). ${ }^{6}$

The current perinatal mortality rate (PMR) of India (2013) is 26 per 1000 births. $^{7}$ It ranges from 16 per 1000 births in urban areas to 28 per 1000 births in rural areas. As with NMR, the PMR is not uniform across the country - the PMR of Kerala is only 9 per 1000 births, whereas that of Odisha is 35 per 1000 births. $^{\text {? }}$

The perinatal mortality in Mumbai as per Brihan Mumbai study analysis in 2013-2014 was 16.46 per 1000 live births. (HMIS dataMaharashtra- Brihan Mumbai-2013-14)

The PMR in our study was 39.65 and the corrected PMR was 36.94, which is slightly higher than the Indian Statistics as well as that of $\mathrm{BMC}$ as our institute has been considered as a newly formed referral centre. Also it has been found to be slightly better than the neighbouring countries of the Indian sub-continent.

The major cause of the perinatal mortality, as described in the Tulip classification, has been found to be prematurity (amongst the known causes), this is a similar finding to a recent prospective study by Baqui et al suggesting the fact that about three-fourth of deaths occurred due to prematurity $(74.8 \%$ ), with $30 \%$ in the first $24 \mathrm{~h}$ (day 0 ) and $<50 \%$ of neonatal deaths secondary to sepsis occur in the first week of life. ${ }^{8}$ In our study too, premature babies accounted for $70 \%$ of all perinatal mortalities; precipitating causes were attributable mainly to septicaemia and pulmonary haemorrhage.

A well-known study by Getachew Bayou in 2012 also mentioned the causes that contributed to the perinatal mortality like obstructed labor, malpresentation, preterm birth, antepartum haemorrhage and hypertensive disorders of pregnancy akin to the observations made in our study as detailed in the sub-groups of the Tulip classification.

The perinatal mortality in our study was found to be highest in the age group of 30-35 years (p-value 0.02) despite lesser number of deliveries (than 25-30 years). A recently published nested case control study done Elias Merdassa Roro et al supports the study's observation, viz mothers aged 35 years and above had a higher risk of losing their newborn babies to perinatal deaths than younger mothers. ${ }^{10}$ Preterm births had a higher risk of perinatal death than term babies. Asphyxia, sepsis and chorioamnionitis were among the leading causes of perinatal deaths.

One of the most important contributor to the perinatal mortality is the lack of awareness and access of the mothers the need for regular antenatal check-ups which has been highlighted in the Agho et $\mathrm{l}^{11}$ This also supports our observation of significant number of perinatal mortalities in the unbooked category.

The etiological factor contributing to the perinatal mortality can be well illustrated with Tulip classification, and most of which are preventable causes. Hence with better antenatal care, and optimization of high risk pregnancies, the goal of reduction in overall infant mortality rate (MDG-4) could be achieved as perinatal mortality adds to the major chunk of it.

\section{ACKNOWLEDGEMENT}

We highly appreciate the valuable contribution by Shaikh Sana in the statistical analysis of the observed data.

\section{REFERENCES}

1. Requejo J, Bryce J, Victora C, Deixel A, on behalf of Countdown to 2015 for Maternal, Newborn and Child Survival. Accountability for Maternal, Newborn \& Child Survival The 2013 Update. WHO and UNICEF: Geneva and New York; 2013

2. D'costa GF, Patil Y. Causes of Mortality in Still Birth - An autopsy study. Bombay 


\section{Hospital J 2007; 49(2)}

3. Kulkarni R, Chauhan S, Shah B, Menon G, Puri C. Investigating causes of perinatal mortality by Verbal Autopsy in Maharashtra, India. Indian J Comm Med 2007; 32(4): 259-63.

4. Liu L, Oza S, Hogan D, Perin J, Rudan I, Lawn JE et al. Global, regional, and national causes of child mortality in 2000-13, with projections to inform post-2015 priorities: an updated systematic analysis. Lancet 2015;385(9966): 430-440.

5. M J Sankar, S B Neogi, J Sharma et al. Journal of Perinatology. State of newborn health in India. 2016 Dec 36(suppl 3) S3-S8

6. World Health Organization. Neonatal and perinatal mortality: country, regional and global estimates. Geneva: World Health Organization; 2006.

7. Dharmendra Raut, Sujata Gujarkar et al. Perinatal Mortality: An Observ Perinatal Mortality: An Observational Study At Tertiary Centre. IOSR Journal of Dental and Mertical Sciences. Volume 16, Issue 9 Ver. I (Sep. 2017), PP 35-38

8. Baqui AH, Darmstadt GL, Williams EK, Kumar V, Kiran TU, Panwar D et al. Rates, Baqui AH, Darmstadt GL, Williams EK, Kumar V, Kiran TU, Panwar D et al. Rates,
timing and causes of neonatal deaths in rural India: implications for neonatal health programmes. Bull World Health Organ 2006; 84: 706-713.

9. Bayou G, Berhan Y.Perinatal mortality and associated risk factors: a case control study Ethiop J Health Sci. 2012 Nov; 22(3): 153-62.

10. Roro EM, Sisay MM, Sibley LM. Determinants of perinatal mortality among cohorts of pregnant women in three districts of North Showa zone, Oromia Region, Ethiopia: Community based nested case control study BMC Public Health. 2018 Jul 18:18(1):888

11. Ghimire PR, Agho KE et al. Perinatal Mortality in South Asia: Systematic Review of Observational Studies. Int J Environ Res Public Health. 2018 Jul 6;15(7). 